\title{
Groundwater faecal pollution observation in parts of Indo-Ganges-Brahmaputra river basin from in-situ measurements and satellite-based observations
}

\author{
Srimanti Duttagupta ${ }^{1, *}$, Animesh Bhattacharya ${ }^{1,2}$, \\ Abhijit MukherJeE ${ }^{1,3}$, Siddhartha Chattopadhyay ${ }^{4}$, \\ SOUMEndRa NATH Bhanja ${ }^{5}$, SOUMYajit SARKAR ${ }^{1}$, \\ Pragnaditya MalakaR ${ }^{3}$ and Jayanta Bhattacharya ${ }^{1,6}$ \\ ${ }^{1}$ School of Environmental Science and Engineering, Indian Institute of Technology, Kharagpur 721 302, India. \\ ${ }^{2}$ Public Health Engineering Department, Government of West Bengal, Kolkata 700 001, India. \\ ${ }^{3}$ Department of Geology and Geophysics, Indian Institute of Technology, Kharagpur 721 302, India. \\ ${ }^{4}$ Department of Humanities and Social Sciences, Indian Institute of Technology, Kharagpur 721 302, India. \\ ${ }^{5}$ Faculty of Science and Technology, Athabasca University, 1 University Dr, Athabasca, AB T9S 3A3, Canada. \\ ${ }^{6}$ Department of Mining Engineering, Indian Institute of Technology, Kharagpur 721302, India. \\ *Corresponding author. e-mail: srimanti.duttagupta@gmail.com
}

MS received 29 November 2018; revised 30 December 2018; accepted 17 January 2019;

published online 22 February 2019

More than quarter of underprivileged global population, who lack access to basic sanitation and clean drinking water, live in India. Consequently, every year, millions suffer with enteric diseases from drinking faecal-contaminated groundwater. The UN Sustainable Development Goal lists access to safe water and basic sanitation for all by 2030, as their sixth goal. For the first time, the role of economic improvement on decrease in water-borne faecal pathogens was studied across Indo-Ganges-Brahmaputra river basin (IGB) for almost last three decades, to delineate the long-term improvement trends of groundwater quality across India, as a consequence of development. Long-term temporal (1990-2017) and high-resolution spatial (administrative block scale, $n=2217$ ) datasets of water-borne faecal pathogen concentration in groundwater and satellite-based nightlight (NL) were used to investigate the statistical trends and causal relationships. Linear and nonlinear (Hodrick-Prescott) trend analyses, panel data analyses, Bayesian vector autoregression (VAR) and lead-lag causality (LLC) analyses were performed on aforesaid culled datasets. However, the efficiency of development in alleviating the water quality and public health, and relationship with economic development, has not been well understood. Here, for the first time, using long-term, high-spatial resolution $(n=2217)$, annual in-situ measurements and multivariate statistical models, we show that the spatially variable groundwater faecal pathogen concentration (FC, 2002-2017, $-1.39 \pm 0.01 \% / y r)$ has been significantly decreased across the basin. In most areas, increasing satellitebased NL plays a significant role (NL, 1992-2013, $3.05 \pm 0.01 \% / y r)$ in reduction of FC. However, in areas with low literacy rate surpass development. Enhanced decrease of faecal coliform concentration in groundwater possibly signifies the implementation of Clean India Mission since 2014.

Keywords. Faecal coliform; nightlight; Indo-Ganges-Brahmaputra basin; sustainable development goal. 


\section{Introduction}

Adequate supply of safe and sustainable water and access to basic sanitation are fundamental right and basic need for human health. Approximately, 1.8 billion people are consuming water having high faecal contamination worldwide, with the majority residing in low- to middle-income countries (Bain et al. 2014). The Sustainable Development Goal (SDG) Goal 6 (UN 2017) aims to increase the access to safe drinking water for major population across the world (Clasen et al. 2012). It has been observed that $51.6 \%$ households across India did not use basic sanitation facility. Hence, drinking water for individual household supply problems remain one of the primary challenges in rural and peri-urban areas in India. The well-being of a society, its development, economics health and essential resource availability are intricately related to each other. It is well known that poverty influences the health of a population in many ways, including exposure to transmitting diseases, food and water insecurity, and lack of access to basic sanitation and water availability. Furthermore, inadequate transport of human excreta to adjacent groundwater due to improper sanitation structure is observed among poverty-stricken populations, leading to severe public health hazard across the world (Adler et al. 1994). Human influences on nature can change the hydrologic cycle forever and worsen water quality. Several studies have been evaluated precipitation-sourced overland flows and associated nutrient transport (Carpenter et al. 1998; Jamieson et al. 2004), but very few studies explain the influence on microbial pollution of water due to anthropogenic activities (Mallin et al. 2000; Martinez 2009). Economically stressed South Asia, predominantly India, having more than $20 \%$ of the global population residing in a $<4 \%$ world's total land cover (Mukherjee et al. 2007, 2009, 2015). In spite of Indian emerging economy, its social economic evolution has been exceedingly bipolar, resulting $70 \%$ of the population under poverty and devoid of safe and sustainable drinking water resources (Huong 2012). This study demonstrates the consequences of economic development on groundwater quality across most populated parts of Indo-Ganges-Brahmaputra river basin (IGB). Approximately, 400 million population reside in IGB encompasses an area of 700,000 $\mathrm{km}^{2}$ (Central Intelligence Agency 2009). This study investigates a long-term spatio-temporal significant effect of satellite-based nightlight (NL, 1992-2013) representing economic development on faecal coliform concentration (FC, 2002-2017) in groundwater sources. To establish the hypothesis on a basin scale, study has been conducted in densely populated Indo-Ganges basin. This study also focuses on effect of population ( $P, 2001-2013)$ and literacy $(L, 2001-2013)$ across the study area and helps to understand the significant role of these parameters on the basis of various statistical approaches.

\section{Methods}

\subsection{Data acquisition and management}

The faecal coliform concentration (FC) data (MPN/ $100 \mathrm{ml}$ ) across IGB have been taken from National Rural Drinking Water Programme (NRDWP), Ministry of Drinking Water and Sanitation, Government of India for 2002-2017. We have acquired information of faecal coliform dissolved in groundwater from 900, 000 locations for more than one decade. These data points have been averaged and upscaled to administrative units $(n=$ 2217). Night-time light (NL) data have been considered as economic development factors. Annual (1992-2013, available at <0.01) satellite-based NL has been measured over the study area from the Defence Meteorological Satellite Program (DMSP) of the US Air Force. The data are processed at administrative unit, i.e., block level (number of blocks in India, $\left.n_{\mathrm{b}}=2217\right)$. Data information of literacy rate $(L, 2001-2013)$ and population $(P$, 2001-2013) have been acquired from Census 2011, Ministry of Home Affairs, Government of India.

\subsection{Water sample collection}

We have obtained the long-term faecal coliform concentrations, as available in the NRDWP, Ministry of Drinking Water and Sanitation, Government of India data archive. Following the methodology reported in NRDWP documentation, the groundwater samples were measured by using membrane filtration method, using membrane lauryl sulphate broth (MLSB) as its selective medium (Rose et al. 1975).

\subsection{Statistical analysis}

Hodrick-Prescott (HP) statistical filter approach has been considered for non-parametric trend 
analysis (Hodrick and Prescott 1997). This study involves panel data analysis to account individual heterogeneity. Panel data refer to sets that consist of both time and series and cross-sectional data (Borenstein et al. 2010). In this study, fixedeffect and random-effect panel data have been used. It is assumed that the error component and the $X$ 's are uncorrelated. Random-effect calculation is advantageous as time invariant variables can be included (Torres-Reyna 2007). Lead-lag causality (LLC) test has been conducted for faecal coliform and NL to understand the lead-lag effect of NL on faecal pollution.

\subsection{Assumptions and uncertainty}

There are several missing data in the archived dataset obtained from the government organisation. Different datasets used in this study were compared for mutually available duration. We have applied possible statistical tests for data filtration in order to upscale it from individual data location to administrative unit scale. We have estimated standard error for each dataset (Gandomi and Haider 2015). Errors associated with FC, NL, $P$ and $L$ have been determined by estimating the standard deviation from the mean. Error estimation has been calculated by the following equation:

$$
\text { Standard error }(\mathrm{SE})=\delta / \sqrt{ } n \text {, }
$$

where $\delta$ is the standard deviation and $n$ is the number of observations.

\section{Results and discussion}

\subsection{Spatio-temporal trend of faecal coliform concentration in groundwater}

FC has been decreased about $79.31 \%$ from 2002 $(\sim 23.7 \mathrm{MPN} / 100 \mathrm{ml})$ to $2017(\sim 4 \mathrm{MPN} / 100 \mathrm{ml})$
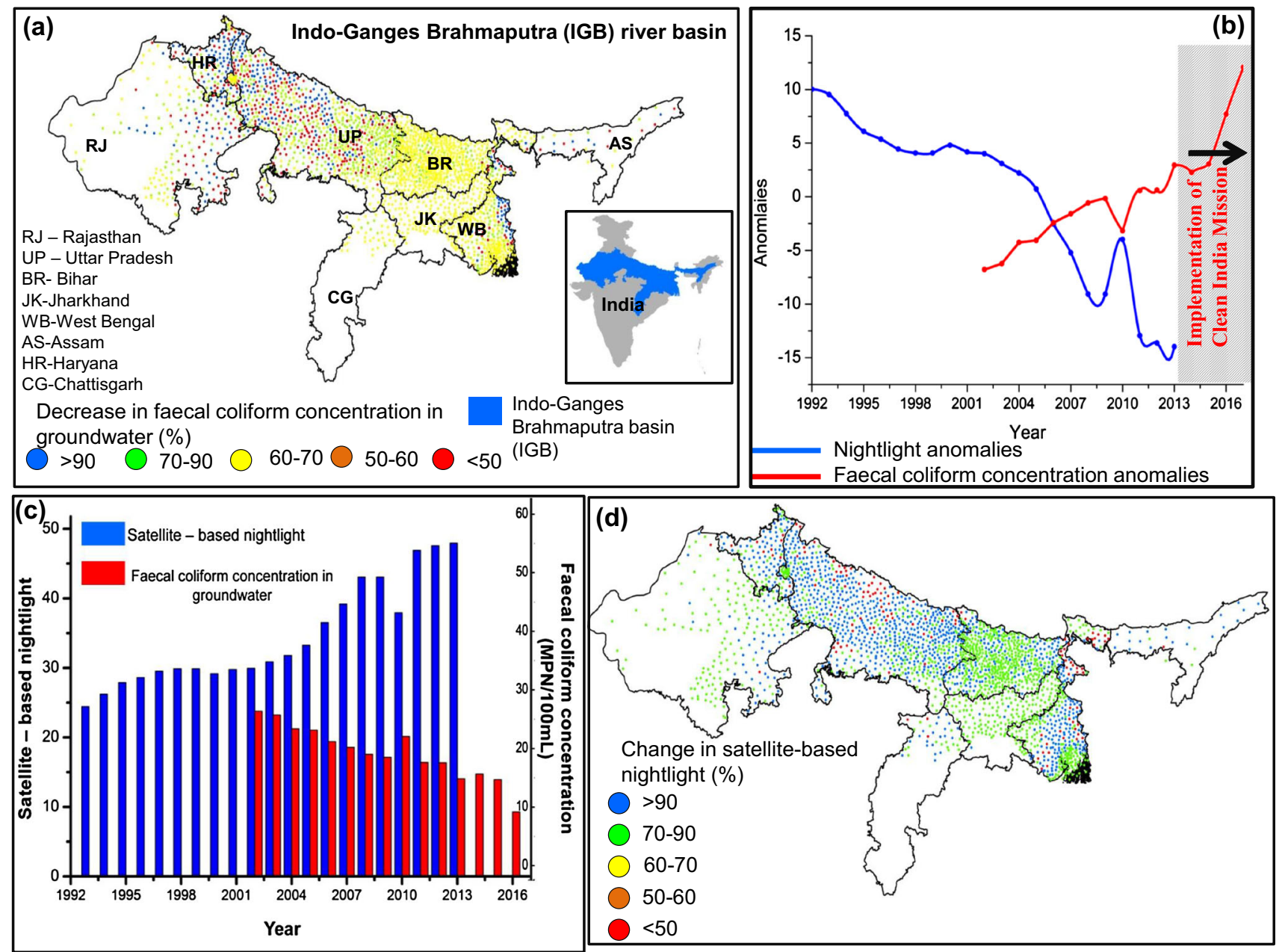

Figure 1. Map showing (a) annual trend of faecal coliform concentration (2002-2017; MPN/100 ml), (b) nonlinear trend faecal coliform concentration and nightlight (1992-2013), (c) change of nightlight and faecal coliform in IGB during 19922013, and (d) linear trend of nightlight across IGB basin. 
across India. The HP analyses show declining faecal coliform concentration trends from 2002 to 2009 with FC decrease at the rate of $1.9 \pm$ $0.003 \% / \mathrm{yr}$ and increase as $1.3 \pm 0.02 \% / \mathrm{yr}$ from 2009 to 2011 (figure 1). Since 2014, it has been observed that faecal coliform concentration trends were found to be decreasing at $2.47 \pm 0.05 \% / \mathrm{yr}$ (figure 1). The enhanced decrease of faecal coliform concentration in groundwater has been observed due to possible effect of Clean India Mission or Swachh Bharat mission (figure 1b) (Swachh Bharat Mission 2017). About 1100 blocks showed more than $90 \%$ cumulative improvement for FC within the study period (highly improved), with another $\sim 150$ units having improvement between $70 \%$ and $90 \%$ (improved) and $\sim 700$ units having $50 \%$ and $70 \%$ (moderately improved; figure 1). However, $\sim 200$ units have $<50 \%$ improvement (less improved; figure 1). Moderately and less-improved areas mostly belong to rural areas, whereas highly improved and improved areas belong to urban and peri-urban areas, respectively. Areas from three different classes have been integrated by using the HP trends.

\subsection{Spatio-temporal trends of socio-economic development and population}

Spatial trend of NL showed an overall increasing trend from 1992 to 2013 (figure 1). It has been observed that NL has been increased about $50.04 \%(2.38 \pm 0.03 \% / \mathrm{yr})$ from the base year 1992 till 2013 for 2217 blocks. Spatial map of NL (figure 1) showed that 1430 blocks improved 80 to $>90 \%$ among 2217 blocks. A total of 531 blocks showed improvement of $60-80 \%$ and around 256 blocks showed moderate increase in NL ( $50 \%)$.

Population $(P)$ and literacy rate $(L)$ have been retrieved from 2001 to 2013 for 2217 blocks (figure 2). The percentage decadal growth of population during 2001-2013 was about $83.9 \%$. It has been observed that urban areas having higher economic activity showed highest increase in literacy of about $79.63 \%$. Literacy rate has been increased at the rate of $2.09 \pm 0.03 \% / \mathrm{yr}$ from 2001 to 2007, and during 2007-2013, it has been decreased to $1.83 \pm 0.05 \% / \mathrm{yr}$ across IGB (figure 2).

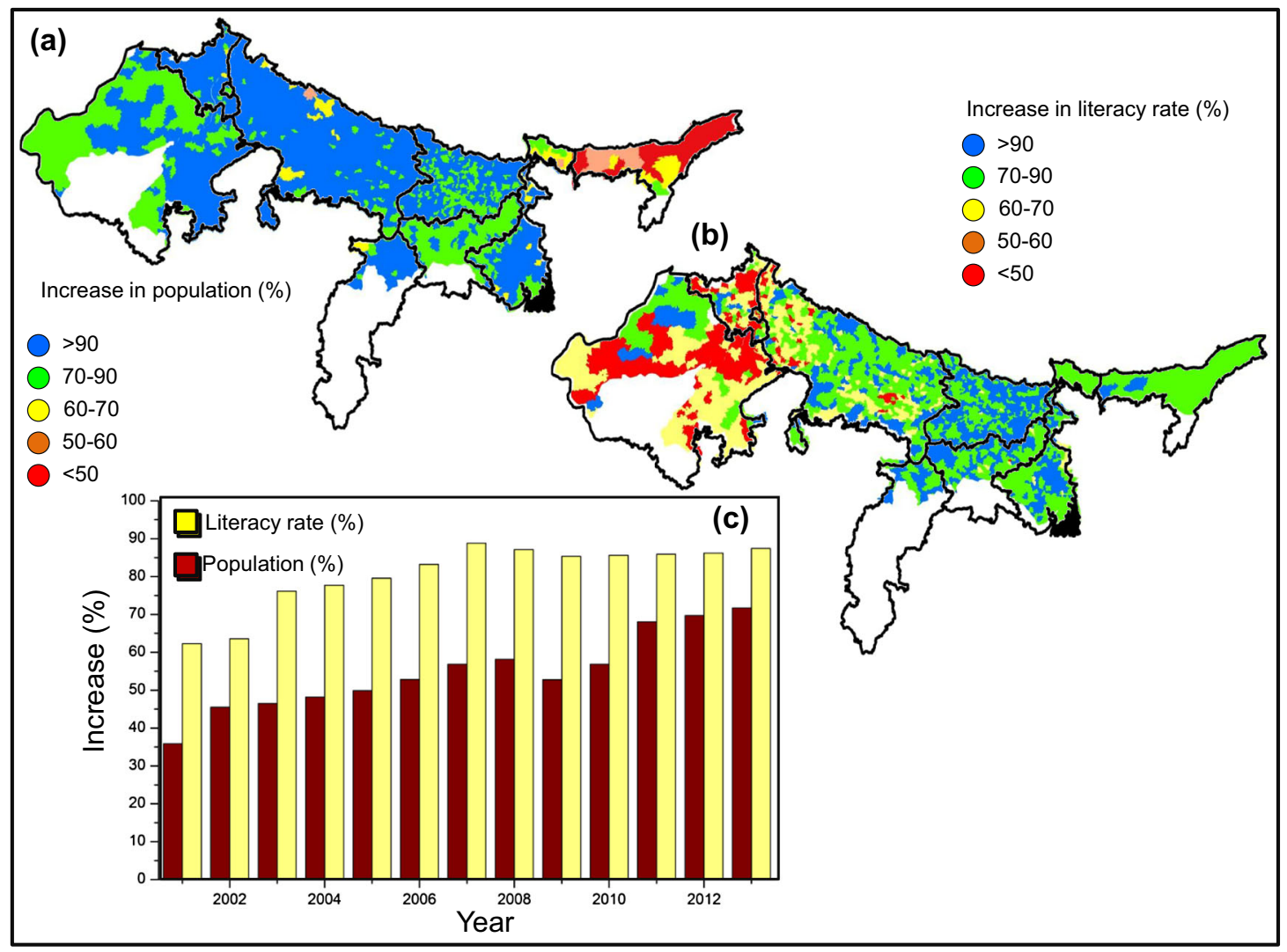

Figure 2. Map of a study area showing annual linear trend of (a) population increase (2001-2013) for 2217 administrative units, (b) increase in literacy rate, and (c) actual change of literacy and population during last decade (2001-2013) across IGB basin. 

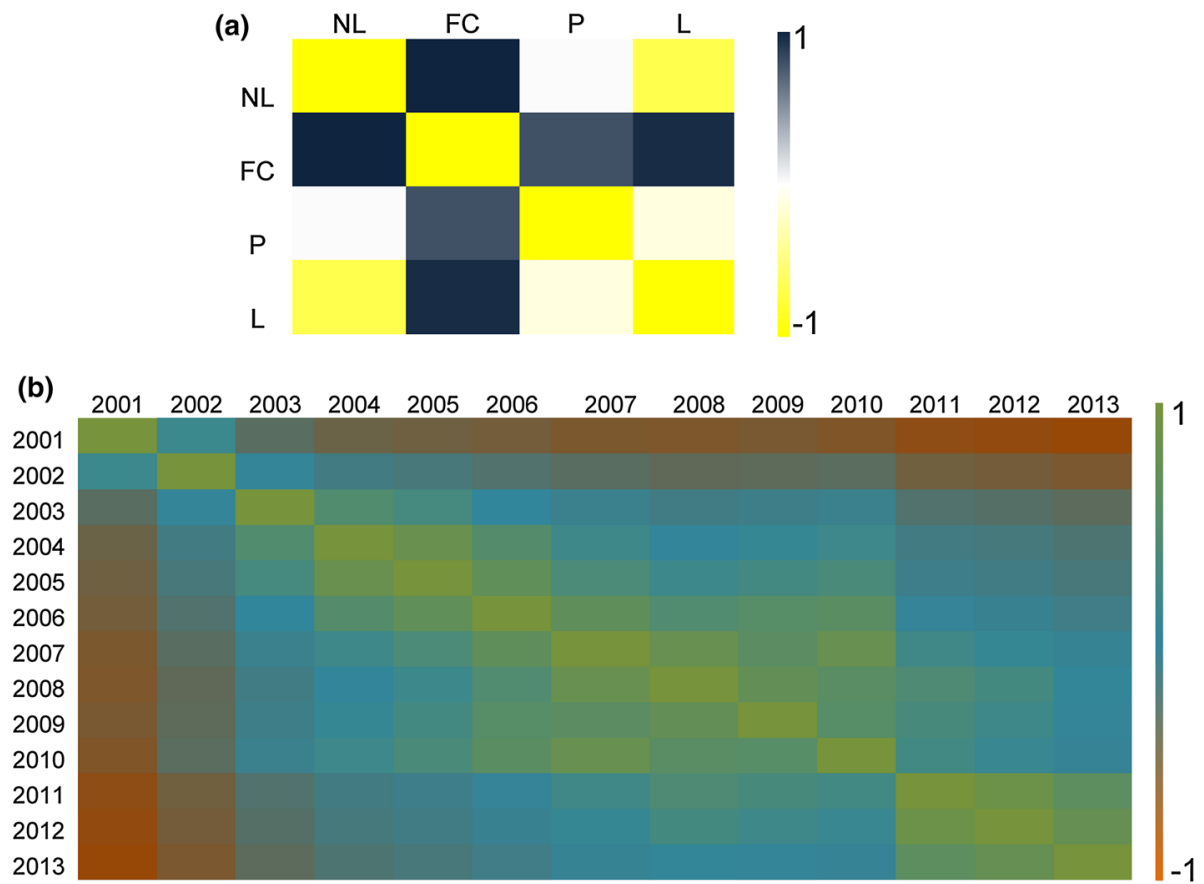

Figure 3. Colour map showing (a) the correlation between faecal coliform, nightlight, population and literacy rate and (b) lead-lag correlation across IGB basin between 1992 and 2013.

\subsection{Influence of economic development on water quality}

To understand the impact of NL, $P$ and $L$ on FC (2002-2013) for the entire study region, we have regressed the data with fixed-effect panel data model. A significant impact of both NL and $L$ on FC was observed (the coefficient associated with NL, $\beta_{\mathrm{NL}}=-0.02$ with $t$-statistic $=-2.05$ $[P<0.01]$ and $L, \beta_{L}=-0.003, t$-statistic $=-2.45$ $[P<0.01])$, suggesting FC improves with the increase in NL and $L$. But $P$ showed a significant positive impact on FC (the coefficient associated with NL, $\beta_{P}=0.001$ with $t$-statistic $\left.=2.34\right)$. FC improves with NL and $L$ in highly and improved region $\left(\beta_{\mathrm{NL}}=-0.91, t\right.$-statistic $=-4.05[P<0.01]$; $\beta_{L}=-0.004, t$-statistic $=-5.19[P<0.01] ; \beta_{P}=$ $0.06, t$-statistic $=2.32[P<0.01]$ for urban areas and $\beta_{\mathrm{NL}}=-0.4, \quad t$-statistic $=-3.02 \quad[P<0.01]$; $\beta_{L}=-0.03, \quad t$-statistic $=-2.84 \quad[P<0.01] ; \quad \beta_{P}=$ $0.01, t$-statistic $=1.07[P<0.01]$ for peri-urban areas). Population does not show a significant impact on faecal coliform decrease across IGB; however, in urban areas, population increase possibly influences increase of faecal pollution into groundwater (figure 3). Faecal pollution has highest effect in 1-year lag $(r=0.94)$, and it decreases over time $(r=-0.6$; figure 3$)$.

\section{Conclusion}

A better knowledge of the prevalence, ecology and distribution of faecal contamination in drinking water source could be an important initiative for development of strategies to reduce public health concern. Most of the potable water samples exceed the standard permissible limit of faecal coliform concentration in rural regions. Suitable environmental condition is the primary reason for faecal coliform growth. As per the study, it has been observed that the area with highest population density decreases the quality of water. Excessive population and slums is an intricate problem which is reflected on all life aspects in low-income countries like India. It has been reflected through results that faecal coliform concentration in urban and peri-urban areas is influenced by population, whereas literacy rate and NL as a proxy of economic development showed an influential role in faecal pollution reduction across IGB. Microbial pollution cannot depend only upon natural parameters; it has to be influenced by other socioeconomic developmental parameters.

We have used spatio-temporal patterns and multivariate statistical models to show the relationship between socio-economic development and faecal coliform concentration. Results show long-term 
(2002-2013) annual decrease of faecal coliform concentrations across 2217 blocks of Indo-GangesBrahmaputra basin. Along with the economic development, societal practice is directly linked with education level. The study indicates that literacy level is one of the primary parameters which can influence prevailing water quality (in terms of FC). As IGB is considered to be the densely populated area in India, population does not show a significant effective relationship with FC. Role of clean India might be important in case of improvement of groundwater quality. Improved sanitation construction and utilization of sanitation are the major key factors which govern the drastic decrease of faecal coliform concentration after 2014. We can conclude that while sanitation development can have a direct influence on public health from water-borne diseases, exogenous factors like societal practices linked to education level, proper human practices, etc., can also exert major influence on water-borne diseases loads of an area.

\section{Acknowledgements}

This study could not have been executed without the cooperation of the Public Health Engineering Directorate and State Water Investigation Directorate, Government of West Bengal. We acknowledge the National Rural Drinking Water Programme, Ministry of Drinking Water and Sanitation, Government of India, for data availability. However, the ideas presented in this paper are those of the authors and have not been officially endorsed by the government or any other person or organisation. We acknowledge the efficient editorial handling by the Associate Editor and constructive review by an anonymous reviewer. We would like to thank Drs Tilottama Ghosh and Sohini Sahu for their constant support on processing of nightlight datasets. Special thanks to Swagata Chakraborty and other colleagues at IIT Kharagpur for their valuable inputs.

\section{References}

Adler N E, Boyce T, Chesney M A, Cohen S, Folkman S, Kahn R L and Syme S L 1994 Socioeconomic status and health: The challenge of the gradient; Am. Psychol. 4915.

Bain R, Cronk R, Hossain R, Bonjour S, Onda K, Wright J, Yang H, Slaymaker T, Hunter P and Prüss-Ustün A
2014 Global assessment of exposure to faecal contamination through drinking water based on a systematic review; Trop. Med. Int. Health $19917-927$.

Borenstein M, Hedges L V, Higgins J P and Rothstein H R 2010 A basic introduction to fixed-effect and randomeffects models for meta-analysis; Res. Synth. Methods 1 97-111.

Carpenter S R, Caraco N F, Correll D L, Howarth R W, Sharpley A N and Smith V H 1998 Nonpoint pollution of surface waters with phosphorus and nitrogen; Ecol. Appl. $8559-568$.

Central Intelligence Agency 2009 The CIA world factbook 2010; Skyhorse Publishing Inc., New York NY 10018, USA.

Clasen T, Fabini D, Boisson S, Taneja J, Song J, Aichinger E, Bui A, Dadashi S, Schmidt W-P and Burt Z 2012 Making sanitation count: Developing and testing a device for assessing latrine use in low-income settings; Environ. Sci. Technol. 46 3295-3303.

Gandomi A and Haider M 2015 Beyond the hype: Big data concepts, methods, and analytics; Int. J. Inf. Manag. 35 $137-144$.

Hodrick R J and Prescott E C 1997 Postwar US business cycles: An empirical investigation; J. Money Credit Bank 29(1) $1-16$.

Huong N T T 2012 Trends of urbanization and suburbanization in southeast Asia; Trends Urban Suburbanization Southeast Asia 325.

Jamieson R, Gordon R, Joy D and Lee H 2004 Assessing microbial pollution of rural surface waters: A review of current watershed scale modeling approaches; Agric. Water Manag. 70 1-17.

Mallin M A, Williams K E, Esham E C and Lowe R P 2000 Effect of human development on bacteriological water quality in coastal watersheds; Ecol. Appl. 101047 1056 .

Martinez J L 2009 Environmental pollution by antibiotics and by antibiotic resistance determinants; Environ. Pollut. 157 2893-2902.

Mukherjee A, Fryar A E and Howell P D 2007 Regional hydrostratigraphy and groundwater flow modeling in the arsenic-affected areas of the western Bengal basin, West Bengal, India; Hydrogeol. J. 151397.

Mukherjee A, Fryar A E and Thomas W A 2009 Geologic, geomorphic and hydrologic framework and evolution of the Bengal basin, India and Bangladesh; J. Asian Earth Sci. 34 227-244.

Mukherjee A, Saha D, Harvey C F, Taylor R G, Ahmed K M and Bhanja S N 2015 Groundwater systems of the Indian sub-continent; J. Hydrol. Reg. Stud. 4 1-14.

Rose R E, Geldreich E E and Litsky W 1975 Improved membrane filter method for fecal coliform analysis; Appl. Microbiol. 29 532-536.

Torres-Reyna O 2007 Panel data analysis fixed and random effects using Stata (v. 4.2); Data Stat Service, Princeton University.

Swachh Bharat Mission 2017 Gramin, Ministry of Drinking Water and Sanitation, Government of India. 